\section{Preliminary study on the correlation of plasma hemolysis index and potassium measurement of inpatient in the Biochemistry Laboratory of General Hospital Kuala Lumpur}

\author{
Chia Zhen Zhan ${ }^{1,2}$, Asma Harun ${ }^{1}$ and Mohd Nazil Salleh ${ }^{1,3^{*}}$ \\ ${ }^{1}$ Department of Medical Technology, Faculty of Health Sciences, Universiti Selangor, Shah Alam \\ Campus, Jalan Zirkon A7/A, Section 7, Shah Alam, Selangor Darul Ehsan, Malaysia; \\ ${ }^{2}$ Core Laboratory, Pathology Department, General Hospital Kuala Lumpur, Jalan Pahang, Wilayah \\ Persekutuan Kuala Lumpur, Malaysia; \\ ${ }^{3}$ Faculty of Health Sciences, PICOMS International University College, Taman Batu Muda, 68100 \\ Batu Caves, Kuala Lumpur, Malaysia.
}

ABSTRACT

Background: Potassium $\left(\mathrm{K}^{+}\right)$is the essential micronutrient and major intracellular fluid cation which involves in various cellular metabolism activities, maintaining fluid and electrolyte balance. Measurement of blood $\mathrm{K}^{+}$concentration in a medical laboratory has often encountered disturbances such as hemolysis, which may lead to the elevation in $\mathrm{K}^{+}$measurement and affects the medical diagnosis and treatment of the patient, conceivably fatal. Hemolysis can be decided using hemolysis index (H-index) through automation. Methods: In this study, $\mathrm{H}$-index and $\mathrm{K}^{+}$ concentration of fifty hospitalized patients $(n=50)$ hemolysed blood samples were measured and correlated. Freezing-and-thaw method was used to hemolyse the blood samples. Different concentrations were diluted and analyzed using COBAS 8000 biochemistry analyser. Data were collected and analyzed using SPSS version 25. Results: Our findings showed significant mean differences, $0.001(\mathrm{p} \leq 0.05)$ and strong positive linear relationship between two variables (H-index and $\left.\mathrm{K}^{+}\right)(\mathrm{r}=0.764, \mathrm{p} \leq 0.05)$. By applying calculated linear equation $\left[\mathrm{y}=0.0048 \mathrm{x}+5.146, \mathrm{R}^{2}=\right.$ 0.5838 ], critical value of $\mathrm{K}^{+} 6.0 \mathrm{mmol} / \mathrm{l}$ gives $\mathrm{H}$-index of 178 , $\mathrm{H}$-index above 178 is suggested to be critical. Discussion and Conclusion: $\mathrm{K}^{+}$concentration increases in proportion to $\mathrm{H}$-index. A greater degree of hemolysis causes more $\mathrm{K}^{+}$ions to be released into extracellular fluid, respectively. In conclusion, when $\mathrm{H}$-index less than 178 in $\mathrm{K}^{+}$measurement and there is no analytical significance bias generated, the result is acceptable, whilst $\mathrm{H}$-index with analyte variation between clinically significant bias range can be released with a comment regarding the potential of data alteration. Meanwhile, result with H-index exceeding the cut-offs should be suppressed and recollection of sample is required.

Keywords: Hemolysis; hemolysed blood; plasma hemolysis index; potassium concentration; specimen integrity.

\section{INTRODUCTION}

Hemolysis is the alteration, dissolution and breakdown of red blood cells or erythrocytes in the blood, rupture of the cell envelope, causing the release of hemoglobin and intracellular contents into the extracellular fluid (Farlex, 2012). Different degrees of hemolysis, either hemolysed in vivo or in vitro, with various concentration of hemoglobin are visible through the process of centrifugation commonly showing pink to red colouration of the plasma or serum (Frank, Bermes, Bickel, \& Watkins, 1978).

Generally, hemolysis is categorized into two, in vivo hemolysis and in vitro hemolysis. In vivo hemolysis happens in body of individual, caused by biochemical, immunological, physical or chemical mechanisms, more than 50 clinical conditions such as autoimmune hemolytic anemia, disseminated intravascular coagulation (DIC), HELLP syndrome erythroparasite infections, oxidant injury, fragmentation injury, histiocytic disorders, inherited red blood cell defects, hemoglobinopathies, heart valves conditions, and also metabolic conditions (Lippi, 2009).

On the other hand, hemolysis is also influenced by in vitro disturbances such as inappropriate or incorrect blood sample collection and processing particularly strongly-forced aspiration while 
puncturing superficial veins with needle and syringe, partial obstruction of an arterial or venous catheter, subsequent splitting of one syringe sample into several tubes, vigorous blood shake, positive or negative pressure in sample tube, blood dilution with hypotonic solution, freezethaw of whole blood, prolonged sample storage, transportation at ambient temperatures, and also blood centrifugation before completion of blood-clotting in plain tube (Frank, Bermes, Bickel, \& Watkins, 1978).

In clinical biochemistry laboratory, hemolysis often detectable spectrophotometrically as traces as low as less than $0.05 \mathrm{~g} / \mathrm{l}$ of free haemoglobin physiologically present in plasma, with upper reference limit for free haemoglobin of $2 \mathrm{mg} / \mathrm{dl}$ for plasma and $5 \mathrm{mg} / \mathrm{dl}$ for serum (Lippi, 2009). Meanwhile, the hallmark of erythrocyte destruction, commonly referred as visible hemolysis conferring slight noticeable pink tinge to the biological matrix with around $0.20 \mathrm{~g} / \mathrm{l}$, (Burtis \& Ashwood, 2010 ) or always exceed $18.8 \mathrm{mmol} / \mathrm{l}$ of free hemoglobin concentration in the plasma with prevalence as high as 3.3\%, accounting for almost $60 \%$ of rejected samples in the clinical laboratories according to Carraro and Plebani, (2007). This gives almost five times higher than the second leading cause of assay interference. In addition, Chemistry Laboratory of University Hospital Luigi Sacco in Milan, Italy, in the year of 2013, had found that significant hemolysis of blood sample occurs in average of $1.15 \%$ of all requested tests which affects around 20,000 determinations per year, mostly from critical care clinical wards, such as neonatology, oncology, and emergency and trauma department (ETD) (Mozzi, Carnevela, Valente \& Pantheghini, 2013)

In concern of hemolysis of blood, the rise of intracellular constituents, spectral and chemical interferences can be a serious disturbance when medical laboratory workers encounter with the hemolysed sample. Hemolysis interference is nearly linear dependent on the final concentration of free haemoglobin in the specimen, generating a consistent trend towards overestimation of components such as lactate dehydrogenase (LDH), alanine transaminase (ALT), aspartate aminotransferase (AST), creatine kinase (CK), creatinine, urea, iron, phosphate, magnesium and total bilirubin (Burtis \& Ashwood, 2010), and especially in the analysis of Potassium $\left(\mathrm{K}^{+}\right)$, an ion selective electrolyte; On the other hand there is a consistent trend towards underestimation of component such as albumin, alkaline phosphatase (ALP), sodium and chloride, gamma glutamyl transferase (GGT), glucose (Lippi, 2009), and degradation of cardiac Troponin T (high sensitivity troponin T: hs-cTnT) (Asirvatham, Moses \& Bjomson, 2013) In addition, traditional assessment has set up a limit of acceptance of 10 percent change in measured components, however as suggested by Lippi (2009), it would be better to adapt an allowable error for interference based on the biological variation of the components.

Potassium $\left(\mathrm{K}^{+}\right)$is the major intracellular cation, with average normal concentration $150 \mathrm{mmol} / \mathrm{l}$ in tissue cells, while in erythrocytes potassium $\left(\mathrm{K}^{+}\right)$presents at an average of $105 \mathrm{mmol} / \mathrm{l}$, approximately twenty-three times the concentration in plasma. Potassium $\left(\mathrm{K}^{+}\right)$is important serving in sodium, potassium -ATPase $\left(\mathrm{Na}^{+}, \mathrm{K}^{+}\right.$-ATPase $)$ pump in controlling nerve impulses and muscle contractility where potassium $\left(\mathrm{K}^{+}\right)$adjusts and maintains the ionic gradients. Potassium $\left(\mathrm{K}^{+}\right)$level in the body is highly dependent on the intake of sodium $\left(\mathrm{Na}^{+}\right)$ and potassium $\left(\mathrm{K}^{+}\right)$, plasma concentrations of mineralocorticoids, and acid-base balance, and daily dietary intake of $50-150 \mathrm{mmol}$ of potassium would be sufficient to fuel individual's body requirement (Burtis, Ashwood, \& Bruns, 2010). Haemolysis often affect the accuracy and precision of biochemistry analysis primarily in potassium $\left(\mathrm{K}^{+}\right)$ measurement, an ion selective electrolyte (Asirvatham, Moses \& Bjomson, 2013). However, this often comes with less or no significant clinical data or evidence. There is a lack of quantitative haemolysis grading or clinically proven index or class in determining the suitability of a hemolysed plasma or serum sample in routine biochemistry analysis in a clinical laboratory. This usually leads to rejection of precious blood sample, or in some cases, test repetition is required. In conjunction, a query in exclusion of other factors is important, those which elevate the potassium $\left(\mathrm{K}^{+}\right)$level such as potassium correction or contamination, otherwise hemolysis would be the main disturbance. Under serum index (SI), there are three panels tested for each blood specimen in heparin tube including hemolysis index (HI), lipemic index (LI), and icteric index (II). Automated hemolysis index (HI) estimates the level of hemolysis of a plasma or serum sample, giving various versions of reading depending on types of analyser. Hemolysis index (HI) can be fantastically useful in determining the suitability in processing a blood specimen as if compared to the traditional way by naked eye observation of a plasma sample colour, or by comparison with a reference colour. It provides an easier and faster way to sample analysis with higher accuracy. However, there are limitations in automated hemolysis index (HI) determination where interference can disturb the accuracy and reliability of results obtained. It is fairly difficult to achieve harmonization in between the available analysers as most of them are of different analytical systems. These analytical systems depend highly on sample quality, hemolysis interference such as in vitro hemolysis, method validation, test-specific hemolysis index (HI) threshold, tolerable bias, hemolysis index (HI) decision threshold, criteria for result interpretation, and also application in clinical practice (Jian, Ji, \& Xiao, 2015). These interferences should be minimized or eliminated in order to ensure the validity of the result produced.

Hence, good monitoring of the hemolysis index can be valuable in solving pre-analytical quality in primary health care, thus reducing unnecessary consequences (Soderberg, Jonsson, Wallin, Grankvist, \& Hultdin, 2009). In addition, it has been shown that hemolysis of patient blood sample may interfere with accurate measurement of analytes such as potassium $\left(\mathrm{K}^{+}\right)$, this further causes the elevation in rate of rejection of sample, showing the highest due to hemolysis, while there is a difficulty in obtaining fresh sample (Usha \& Yogish, 2016).

Correlation of Plasma Hemolysis Index and Potassium Measurement of Inpatient in the Biochemistry Laboratory of General Hospital Kuala Lumpur is useful to appraise the knowledge and function of plasma hemolysis index (HI) in the assessment of potassium $\left(\mathrm{K}^{+}\right)$level of inpatient, which helps in the maximization of blood sample usage for clinical biochemistry analysis, henceforth allowing reduction of precious blood sample frequent rejections, and diminish the cost of reagents and materials, time consumption, higher labour workload, and delaying the treatment of the patient (Boris, Bartholomew, Martin, \& Barry, 2014). This study targets to optimize the plasma $\mathrm{H}$-index in measurement of $\mathrm{K}^{+}$ level of inpatient in which the suitability of the sample for measurement of $\mathrm{K}^{+}$concentration can be easily determined using critical $\mathrm{H}$-index. Nevertheless, this study also aims to determine the critical value (cut-off value) of $\mathrm{H}$-index in measurement of $\mathrm{K}^{+}$level of inpatient and $\mathrm{H}$-index will be correlated with the upper critical limit of $\mathrm{K}^{+}(6.0 \mathrm{mmol} / \mathrm{L})$ once the relationship of $\mathrm{H}$-index and $\mathrm{K}^{+}$measurement is determined.

\section{MATERIALS AND METHODS Blood sampling}

A total of 50 (19 females, 31 males; median age 53.5 years, interquartile range 21-30 years) secondary laboratory blood samples (plasma) in lithium heparin tubes from inpatients of General Hospital Kuala Lumpur in accordance to inclusion and exclusion criteria: normal HI $(<90)$, no prolonged sample, no outpatient sample, no clotted sample, no hematological or critically-ill patient sample, and no naturally hemolysed sample. The quantity of sample is in accordance with CLSI EP9-A guideline: User Comparison of Quantitative Clinical Laboratory Methods Using Patient Sample, with a minimum of forty $(n=40)$ as suggested by CLSI.

\section{Analysis of hemolysis index and potassium concentration}

All blood samples were centrifuged under $3500 \mathrm{rpm}$ for 5 minutes to separate packed cells and plasma. Aliquoted plasma was analyzed for $\mathrm{H}$-index and $\mathrm{K}^{+}$concentration using ROCHE COBAS 8000 biochemistry analyzer. Meanwhile packed cells in lithium heparin tubes were placed in a horizontal position in a freezer at $-20^{\circ} \mathrm{C}$ for 15 minutes, removed and thawed quickly with warm running tap water. This is freezing-and-thaw method for blood hemolysis (Lovelock, 1953). This method was chosen to prevent any pre-dilution or pre-increment of any 
ion selective electolytes. Hemolysed blood were then added into plasma in four hemolysis concentration gradients and analyzed (Figure 1). Rapid processing was required to prevent analysis error.

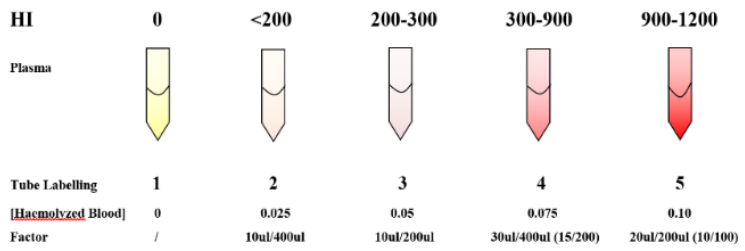

Figure 1: Development of a plasma sample with increasing concentration gradient (degree of hemolysis). ${ }^{*}$ Differences in individual appearance is difficult to distinguish from each level (an increase of level in steps of 100, starting from 'zero").

\section{Data collection and analysis}

Each sample in one originally non-hemolysed plasma and four different hemolysis concentration plasma as a set of data. Data were analyzed with SPSS version 22.0 using one-way ANOVA to determine the increment and mean of results of $\mathrm{H}$-index and $\mathrm{K}^{+}$measurement, post-hoc test to prove the differences in data values, while Pearson's correlation was used to evaluate the relationship of variables and interpreted based on Guilford's Rule of Thumb, 1956 (Table 1).

Table 1: Guilford's Rule of Thumb (Guilford, 1956)

\begin{tabular}{cc}
\hline Coefficient, $\mathrm{r}$ & Interpretation \\
\hline$<0.20$ & Very weak \\
$0.20-0.40$ & Weak \\
$0.40-0.70$ & Moderate \\
$0.70-0.90$ & Strong \\
$>0.90$ & Very strong \\
\hline
\end{tabular}

\section{Ethical consideration}

Ethical approvals were given by Ethical Committee of Faculty of Engineering and Life Sciences (ECFELS), Universiti Selangor with reference number J150056E; and Medical Research and Ethics Committee (MREC), Ministry of Health Malaysia (KKM) with reference number NMRR-16-2148-29653 (IIR).

\section{RESULTS}

\section{Descriptive analysis}

From the total of 50 samples inpatients, 8 samples (16\%) were below 30 years old, 8 samples (16\%) were within 30-40 years old, 7 samples (14\%) between 41-50 years old, and 6 samples (12\%) between 51-60 years old and 21 samples (42\%) were from age 61 and above (Figure 2).

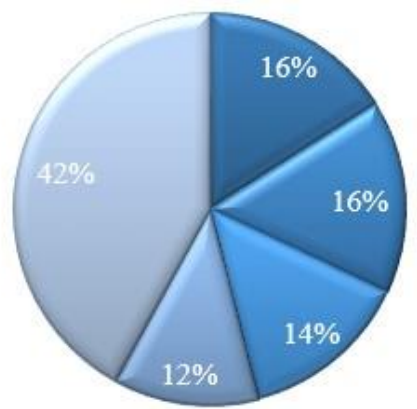

a $30 \quad \mathbf{a} 30-40 \square 41-50 \square 51-60 \quad \square>60$

Figure 2: Age distribution of inpatients

Meanwhile, 19 samples (38\%) were from female inpatients and 31 samples $(62 \%)$ were from male inpatients (Figure 3). Regarding ethnicity, majority of the samples were from Malay inpatients consisting of 31 samples (62\%), 10 samples (20\%) were from Chinese inpatients, and 9 samples (18\%) were from Indian inpatients (Figure 4).

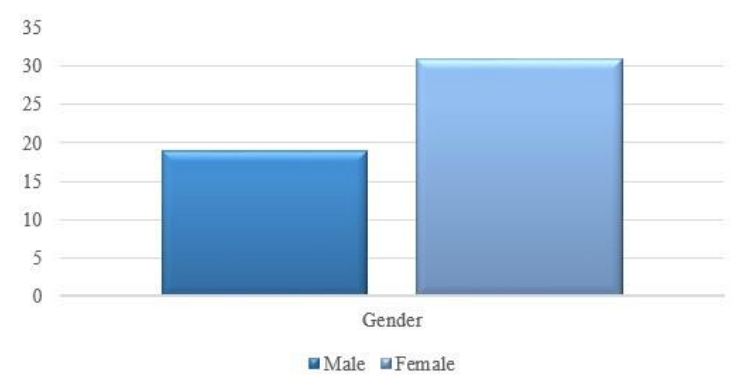

Figure 3: Distribution between gender of inpatients

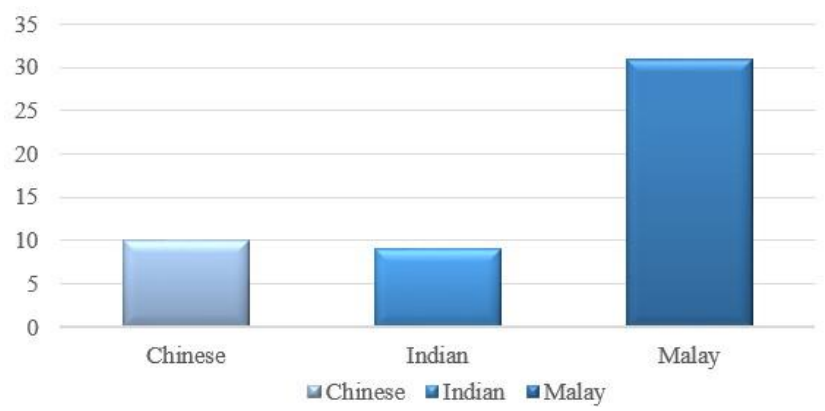

Figure 4: Comparison between the ethnicity of inpatients

\section{Inferential Analysis \\ Variance of potassium measurement and hemolysis index}

Mean square between groups of $\mathrm{K}^{+}$measurement 219.451 and mean square within group 1.880 (Table 2); mean squares of $\mathrm{H}$-index between groups 4386295.101 and within group 64956.224 (Table 3) were calculated using one-way ANOVA. With ratio of differences for $\mathrm{K}^{+}$ measurement $\mathrm{F}=116.703$ and $\mathrm{F}=67.527$ for $\mathrm{H}$-index, there is a statistically significant difference between the mean $(\mathrm{p} \leq 0.05)$.

Table 2: One-way ANOVA for Potassium $\left(\mathrm{K}^{+}\right)$Measurement

\begin{tabular}{lccc}
\hline & Mean Square & F & Sig. \\
\hline Potassium & & & \\
Between Group & 219.451 & 116.703 & .0001 \\
Within Group & 1.880 & & \\
\hline \multicolumn{2}{c}{ The mean difference is significant at the 0.05 level }
\end{tabular}

The mean difference is significant at the 0.05 level

Table 3: One-way ANOVA for Hemolysis Index (HI)

\begin{tabular}{lccc}
\hline & Mean Square & F & Sig. \\
\hline Potassium & & & \\
Between Group & 4386295.101 & 67.527 & .0001 \\
Within Group & 64956.224 & & \\
\hline
\end{tabular}

The mean difference is significant at the 0.05 level

Differences between both potassium measurement groups and hemolysis index groups

Since there is an overall statistical difference in group means as shown in the variance of potassium measurement and hemolysis index, the post-hoc tests for both $\mathrm{K}^{+}$measurement (Table 4) and $\mathrm{H}$-index (Table 5) has shown differences in data value with significant value $\mathrm{p} \leq$ 0.05 . 
Table 4: Post Hoc Tests for Potassium $\left(\mathrm{K}^{+}\right)$Measurement (Tukey HSD)

\begin{tabular}{cccccr}
\hline \multicolumn{2}{c}{ [Hemolysed Blood] } & $\begin{array}{c}\text { Mean } \\
\text { Difference }\end{array}$ & Sig. & \multicolumn{2}{c}{$95 \%$ CI } \\
\hline (I) & $(\mathrm{J})$ & \multicolumn{1}{c}{$(\mathrm{I}-\mathrm{J})$} & & \multicolumn{1}{c}{ LB } & \multicolumn{1}{c}{$\mathrm{UB}$} \\
\hline$[0.000]$ & {$[0.025]$} & -1.39500 & .0001 & -2.1487 & -.6413 \\
& {$[0.050]$} & -2.81280 & .0001 & -3.5665 & -2.0591 \\
& {$[0.075]$} & -3.70200 & .0001 & -4.4557 & -2.9483 \\
& {$[0.100]$} & -5.44780 & .0001 & -6.2015 & -4.6941 \\
\hline$[0.025]$ & {$[0.000]$} & 1.39500 & .0001 & .6413 & 2.1487 \\
& {$[0.050]$} & -1.41780 & .0001 & -2.1715 & -.6641 \\
& {$[0.075]$} & -2.30700 & .0001 & -3.0607 & -1.5533 \\
& {$[0.100]$} & -4.05280 & .0001 & -4.8065 & -3.2991 \\
\hline$[0.050]$ & {$[0.000]$} & 2.81280 & .0001 & 2.0591 & 3.5665 \\
& {$[0.025]$} & 1.41780 & .0001 & .6641 & 2.1715 \\
& {$[0.075]$} & -.88920 & .0121 & -1.6429 & -.1355 \\
& {$[0.100]$} & -2.63500 & .0001 & -3.3887 & -1.8813 \\
\hline$[0.075]$ & {$[0.000]$} & 3.70200 & .0001 & 2.9483 & 4.4557 \\
& {$[0.025]$} & 2.30700 & .0001 & 1.5533 & 3.0607 \\
& {$[0.050]$} & .88920 & .0121 & .1355 & 1.6429 \\
& {$[0.100]$} & -1.74580 & .0001 & -2.4995 & -.9921 \\
\hline$[0.100]$ & {$[0.000]$} & 5.44780 & .0001 & 4.6941 & 6.2015 \\
& {$[0.025]$} & 4.05280 & .0001 & 3.2991 & 4.8065 \\
& {$[0.050]$} & 2.63500 & .0001 & 1.8813 & 3.3887 \\
& {$[0.075]$} & 1.74580 & .0001 & .9921 & 2.4995 \\
\hline
\end{tabular}

The mean difference is significant at the 0.05 level

\section{DISCUSSION AND CONCLUSION}

Nowadays serum hemolysis index is a popular solution for interference detection pre-analytically. Manufacturers give the list of test-specific serum indices for hemolysis, lipemia and bilirubin interferences. This can help biochemist or laboratory personal to be aware of interference, study or reject the sample, and add comments to the results. But the standardization problem of the various analytical systems and different decision thresholds for various serum indices requires more effort (Simundic, Topic, Nikolac, \& Lippi, 2010).

In this study, the majority of samples received were from elderly inpatients. Lack of awareness and education in concern of health statuses led to this situation. A study of Public Health Awareness among Elderly in an Industrially Developing Country in Malaysia shown that $85 \%$ of Malaysian from three states of age $\geq 40$ had $\geq 1$ disease (Ruhana, Norshaied, Syaidatul, Paul \& Loo, 2011). Correspondingly, this study also showed that male inpatients had a higher frequency than female, which was also found in the public health awareness study found that men and women had different diseases (Ruhana, Norshaied, Syaidatul, Paul \& Loo, 2011) and different ethnicity affected the type of disease ( Geok, 1994).

Meanwhile, statistical analysis in this study proved the correlation of hemolysis and $\mathrm{K}^{+}$concentration. With $\mathrm{p} \leq 0.05$, one-way ANOVA test showed differences in means between and within the group of $\mathrm{K}^{\wedge}+$ concentration and $\mathrm{H}$-index. The data values were not equal and had significant differences, as different level of hemolysis releases different concentration of $\mathrm{K}^{+}$. In a study of interference by haemolysis in the cardiac troponin $\mathrm{T}$ immunoassay, various intracellular components such as $\mathrm{K}^{+}$and phosphate were released increasingly with the increase of hemolysis (Sodi, Darn, Davison, Scott \& Shenkin, 2013).

Hemolysis is one of the huge factors in concern of causing elevation of various intracellular components, through the damaging and disruption of cellular membranes (Lippi, 2009). In vitro hemolysis has been identified as the biggest contribution secondary to in vivo hemolysis, since naturally occurring hemolysis is unavoidable, for instance, autoimmune hemolytic anemia (AIHA). Undesirable consequences may follow when the falsely shifted biochemistry results were released for clinical management, such as mistreatment medically or surgically. Hemolysis can be detected visually, and estimation through direct analysis is so indispensable which hemolysis index (HI) is functional in this regard (Usha \& Yogish, 2016).

Remarkably, the correlation study in between $\mathrm{K}^{+}$measurement
Table 5: Post Hoc Tests for Hemolysis Index (HI) (Tukey HSD)

\begin{tabular}{cccccc}
\hline \multicolumn{2}{c}{$\begin{array}{r}\text { [Hemolysed } \\
\text { Blood] }\end{array}$} & $\begin{array}{c}\text { Mean } \\
\text { Difference }\end{array}$ & Sig. & \multicolumn{2}{c}{$95 \%$ CI } \\
\hline (I) & $(\mathrm{J})$ & \multicolumn{1}{c}{$(\mathrm{I}-\mathrm{J})$} & & $\mathrm{LB}$ & \multicolumn{1}{c}{$\mathrm{UB}$} \\
\hline$[0.000]$ & {$[0.025]$} & -93.42000 & .357 & -233.5041 & 46.6641 \\
& {$[0.050]$} & -254.86320 & .0001 & -394.9473 & -114.7791 \\
& {$[0.075]$} & -426.92000 & .0001 & -567.0041 & -286.8359 \\
& {$[0.100]$} & -747.42000 & .0001 & -887.5041 & -607.3359 \\
\hline$[0.025]$ & {$[0.000]$} & 93.42000 & .357 & -46.6641 & 233.5041 \\
& {$[0.050]$} & -161.44320 & .015 & -301.5273 & -21.3591 \\
& {$[0.075]$} & -333.50000 & .0001 & -473.5841 & -193.4159 \\
& {$[0.100]$} & -654.00000 & .0001 & -794.0841 & -513.9159 \\
\hline$[0.050]$ & {$[0.000]$} & 254.86320 & .0001 & 114.7791 & 394.9473 \\
& {$[0.025]$} & 161.44320 & .015 & 21.3591 & 301.5273 \\
& {$[0.075]$} & -172.05680 & .008 & -312.1409 & -31.9727 \\
& {$[0.100]$} & -492.55680 & .0001 & -632.6409 & -352.4727 \\
\hline$[0.075]$ & {$[0.000]$} & 426.92000 & .0001 & 286.8359 & 567.0041 \\
& {$[0.025]$} & 333.50000 & .0001 & 193.4159 & 473.5841 \\
& {$[0.050]$} & 172.05680 & .008 & 31.9727 & 312.1409 \\
& {$[0.100]$} & -320.50000 & .0001 & 460.5841 & -180.4159 \\
\hline$[0.100]$ & {$[0.000]$} & 747.42000 & .0001 & 607.3359 & 887.5041 \\
& {$[0.025]$} & 654.00000 & .0001 & 513.9159 & 794.0841 \\
& {$[0.050]$} & 492.55680 & .0001 & 352.4727 & 632.6409 \\
& {$[0.075]$} & 320.50000 & .0001 & 180.4159 & 460.5841 \\
\hline & The mean difference is significant at the 0.05 level & \\
& & & & &
\end{tabular}

and $\mathrm{H}$-index showed a strong positive linear correlation ( $\mathrm{p} \leq 0.05)$. The greater the hemolysis, the higher the $\mathrm{K}^{+}$concentration. This is supported by the study of Correlation and reporting of $\mathrm{K}^{+}$results in haemolysed samples (Dimeski, Clague \& Hickman, 2005) and the study of Correction factors for estimating $\mathrm{K}^{+}$concentrations in samples with in vitro hemolytic hemolysis: a detriment to patient safety ( Mansour, Azzazy \& Kazmierczak, 2009). Meanwhile, in the study of Use of Hindex to estimate $\mathrm{K}^{+}$concentration in in-vitro haemolysed serum samples, linear relationship derived for patients showed a $\mathrm{K}^{+}$increament of around $0.16 \mathrm{mmol} / \mathrm{l}$ for every increment in the H-index (Shepherd, Warner, Poon, \& Kilpatrick, 2006). This proved the existence of linear correlation, which was represented in Figure 3.4.

The highlight of this study is the effect of hemolysis through correlation of hemolysis index (HI) and potassium $\left(\mathrm{K}^{+}\right)$concentration. Based on research conducted, the null hypothesis was rejected. Hence, there is a significant correlation $(\mathrm{p} \leq 0.05)$ between haemolysis index (HI) and potassium $\left(\mathrm{K}^{+}\right)$measurement. As haemolysis index (HI) increases, potassium $\left(\mathrm{K}^{+}\right)$concentration will increase. The relationship between both of them is a linearly strong positive. This shows that haemolysis releases potassium ions $\left(\mathrm{K}^{+}\right)$into surrounding fluid increasing the ion concentration, considered as pseudohyperkalamia, which can be easily confused with the potentially life-threatening hyperkalamia. Through the positive linear correlation $\left(\mathrm{R}^{2}=0.5838\right)$ in between haemolysis index $(\mathrm{HI})$ and potassium $\left(\mathrm{K}^{+}\right)$, critical hemolysis index can be decided. This linear equation derived $y=0.0048 x+5.146$ $\left(\mathrm{R}^{2}=0.5838\right)$, allows the finding of critical H-index, which is 178 . This shall be useful in deciding the acceptancy of a hemolysed plasma sample for a biochemistry analysis.

In conjunction with sample hemolysis issue, both laboratory personnel and medical management team should be fully responsible upon the primer care of sample quality in order to produce accurate, precise, and reliable blood analysis results for a better health care management and disease treatment. Prevention steps of sample hemolysis should be well practised in pre-analytical, analytical and finally post-analytical processes. This could tremendously reduce unnecessary rejection of sample, repetition of test, inaccurate laboratory result releasing, and thereafter problems which may be fatal. Additionally, in future, the quality of study shall be improved by increasing the size of the population i.e. the number of samples, volume of sample, and longer period of time for conduction of study to increase the accuracy and precision of the result, and to minimize error. A more specific method of blood hemolysing shall be practised and hemolysed 
blood concentration shall be studied. Comparisons of the result between various analytes should be performed. Infield, strategies should be adopted in order to prevent hemolysis.

In conclusion, when $\mathrm{H}$-index less than 178 in $\mathrm{K}^{+}$measurement and there is no analytical significance bias generated, the result of the $\mathrm{K}^{+}$level test is acceptable, whilst $\mathrm{H}$-index with analyte variation between clinically significant bias range can be released with a comment regarding the potential of data alteration. Hemolysed blood with elevated potassium $\left(\mathrm{K}^{+}\right)$concentration which passes the cut-off value of hemolysis index $\mathrm{HI}=178$, may be considered as pseudo-elevation and result should be suppressed, rejected and recollection of sample is required instead of repeating the test, which is time ineffective, costconsuming and labour-burdening. This may help in avoiding releasing result with pseudohyperkalamia which may cause mistreatment of patient and probably intolerable consequences (Asirvatham, Moses \& Bjomson, 2013). Somehow, this avoidable error may become the primary cause of delayed treatment of the patient in a medical emergency.

\section{DISCLOSURES}

No conflict of interest exists in this manuscript, and the manuscript is approved by all authors for publication. The funding organization played no role in the study design; in the sample collection, analysis, and interpretation of data; in writing of the report; or in the decision to submit the report for publication.

\section{ACKNOWLEDGEMENTS}

Immeasurable appreciation and deepest gratitude are extended to individuals involved in all kind of contribution to this research particularly from Core Laboratory Unit, Pathology Department, General Hospital Kuala Lumpur as part of the Ministry of Health, Malaysia. This research received no specific grant from any funding agency in the public, commercial, or not-for-profit sectors but rather supported by the Department of Health Sciences, Faculty of Engineering and Life Sciences (FELS), Universiti Selangor, Shah Alam Campus, Selangor Darul Ehsan.

\section{REFERENCES}

Asirvatham, J. R., Moses, V., \& Bjomson, L. (2013). Error in potassium measurement: A laboratory perspective for the clinician. North American Journal of Medical Sciences, 5(4). 255-259. Crossref $\mid$ Google Scholar

Boris, K., Bartholomew, C., Martin, L., \& Barry, H. (2014). Do hemolyzed potassium specimen need to be repeated? The Journal of Emergency Medicine, 47(3). 313-317. Crossref $\mid \underline{\text { Google Scholar }}$

Burtis, C. A., Ashwood, E. R., Bruns, D. E. (2010). Tietz Fundamental of Clinical Chemistry (6th ed.). New Delhi: Reed Elsevier India Private Limited.

Dimeski, G., Clague, A., \& Hickman, P. (2005). Correction and reporting of potassium results in haemolysed samples. Annals of Clinical Biochemistry, 42. 119-123. Crossref $\mid$ Google Scholar

Frank, J. J., Bermes, E. W., Bickel, M. J., \& Watkins, B. F. (1978). Effect of in vitro haemolysis on chemical values for serum. Clinical Chemistry, 24(11). 19661970. Crossref | Google Scholar

Geok, L. K. (1994). Ethnic characteristics of coronary heart disease risk factors and mortality in Peninsular Malaysia. Asia Pacific Journal of Clinical Nutrition, 3. 93-98. Crossref | Google Scholar

Jian, B. Z., Ji, L., \& Xiao, D. Z. (2015). Analysis of bias in measurements of potassium, sodium, and haemoglobin by an emergency department-based blood gas analyser relative to hospital laboratory autoanalyzer results. PloS ONE, 10(4). 1-6. Crossref $\mid$ Google Scholar

Lippi, G. (2009). In vitro haemolysis: Causes, prevalence, effects, measurement and solutions. Innsbruck. Retrieved from http://www.specimencare.com/resource.aspx?IDX=11331.

Lovelock, JE. (1953). The haemolysis of human red blood cells by freezing and thawing. Biochem Biophys Acta (AMST), 10. 414-26. Crossref | Google $\underline{\text { Scholar }}$

Mansour, M., Azzazy, H., \& Kazmierczak, S. (2009). Correction factors for estimating potassium concentrations in samples with in vitro haemolysis: a detriment to patient safety. Archives of Pathology \& Laboratory Medicine Journals, 133(6). 960-966. Crossref $\mid$ Google Scholar
Medical Dictionary for the Health Professions and Nursing. (2012). Farlex. Retrieved from http://medical-dictionary-thefreedictionary.com/haemoysis.

Mozzi, R., Carnevela, A., Valente, C., Dolci A., \& Pantheghini, M. (2013) Recording, monitoring, and managing pre-analytical issues in a metropolitan university hospital. (Biochem CI). Crossref $\mid \underline{\text { Google Scholar }}$

Ruhana, Z., Norshaieda, A., Syaidatul, Z. M. D., Paul, H. P. Y., \& Loo, H. S. (2011). A study of public health awareness among the elderly in an industrially developing country. Journal of Social Sciences, 7(2). 152-157. Crossref | Google Scholar

Shepherd, J., Warner, M., Poon, P., \& Kilpatrick, E. (2006). Use of heamolysis index to estimate potassium concentration in in-vitro haemolysed serum samples. Clinical Chemistry and Laboratory Medicine, 44(7). 877-879. Crossref | Google Scholar

Simundic, AM., Topic, E., Nikolac, N., Lippi, G. (2010). Hemolysis detection and management of hemolysed specimens. Biochemia Medica, 20. 154-9. Google $\underline{\text { Scholar }}$

Soderberg, J., Jonsson, P. A., Wallin, O., Grankvist, K., \& Hultdin, J. (2009). Haemolysis index- An estimate of preanalytical quality in primary health care. Clinical Chemistry and Laboratory Medicine, 47(8). 940-944. Crossref | Google Scholar

Sodi, R., Darn, S., Davison, A., Scott, A., \& Shenkin, A, (2006). Mechanism of interference by haemolysis in the cardiac troponin T immunoassay. Annals of Clinical Biochemistry, 43. 49-56. Crossref $\mid \underline{\text { Google Scholar }}$

Usha, A. \& Yogish, S. (2016). Hemolytic index- A tool to measure hemolysis in vitro. Journal of Biotechnology and Biochemistry (IOSR-JBB), 2(2). 49-52. Google Scholar

Copyright (C) 2020 by the Author(s). Life Sciences, Medicine and Biomedicine (ISSN: 2600-7207) Published by Biome Journals - Biome Scientia Sdn Bhd. Attribution-ShareAlike 4.0 International (CC BY-SA 4.0). This open access article is distributed based on the terms and conditions of the Creative Commons Attribution license https://creativecommons.org/licenses/by-sa/4.0/ 